\title{
La descolonización del derecho y la justicia comunitaria em el marco del nuevo constitucionalismo latinoamericano
}

The decolonization of community law and justice within the framework of the new Latin American constitutionalism

A descolonização do direito e da justiça comunitária no marco do novo constitucionalismo latino-americano

La décolonisation du droit et la justice communautaires dans le cadre du nouveau constitutionnalisme latino-américain

新拉美宪政主义框架内的社区法律与正义的非殖民化

Gisele Ricobom ${ }^{1} \quad$ Universidad Federal

Félix Pablo Friggeri ${ }^{2}$ de la Integración Latinoamericana

Revista Derechos en Acción ISSN 2525-1678/ e-ISSN 2525-1686

Año 4/No 12 Invierno 2019 (21 junio a 20 septiembre), 190-209

DOI: https://doi.org/10.24215/25251678e305

ORCID: https://orcid.org/ 0000-0001-6634-818X

https://orcid.org/0000-0001-9365-6698

Recibido:15/05/2019

Aprobado:17/06/2019

Resumen: El trabajo aborda una de las categorías teóricas más ricas y dinámicas sobre la estructuración injusta de la realidad latinoamericana

\footnotetext{
1 Profesora del curso de Relaciones Internacionales e Integración y de la Maestría en Integración Contemporánea de América Latina - ICAL, de la Universidad Federal de la Integración Latinoamericana - UNILA. Actualmente en cooperación con la Facultad Nacional de Derecho, de la UFRJ. Doctora en Derecho por la Universidad Pablo de Olavide, España.

2 Profesor del curso de Relaciones Internacionales e Integración y de la Maestría en Integración Contemporánea de América Latina - ICAL, de la Universidad Federal de la Integración Latinoamericana - UNILA. Doctor en Ciencias Sociales, Universidad Nacional de Entre Ríos, Argentina
} 
es aquella revelada por la colonialidad del poder y del saber, no solo como una perspectiva de análisis del pasado, sino sobre todo como una reflexión permanente y actual que posee una extrema capacidad de penetración en todas las camadas sociales de América Latina. Los estudios descoloniales permitirán visibilizar los mecanismos coloniales arraigados en las estructuras institucionales del Estado y de la sociedad latinoamericana. La emergencia de una sociología decolonial contribuye vivamente para pensar y construir otra posibilidad de justicia, resultado de una legalidad subalterna que refunda el orden constitucional sobre bases profundamente innovadoras. Concluye sus autores que el proceso de descolonización es continuo, la justicia comunitaria es apenas una de sus estrategias más importantes, pero es una fuente preciosa e inmensa para repensar el derecho a partir de los valores populares, libertándolo de su atadura servil a la propiedad burguesa.

Palabras claves: descolonización jurídica- justicia comunitaria-constitucionalismo latinoamericano

Abstract: This paper addresses one of the richest and most dynamic theoretical categories about the unfair structuring of Latin American reality. It is revealed by the coloniality of power and knowledge, not only as a perspective of analysis of the past, but above all as a permanent and current reflection that has an extreme capacity for penetration in all social strata of Latin America. Studies with a decolonial perspective will make visible the colonial mechanisms rooted in the institutional structures of the State and of Latin American society. The emergence of a decolonial sociology contributes strongly to think and build another possibility of justice, the result of a subaltern legality that refuses the constitutional order on deeply innovative bases. In conclusion the decolonization process is continuous, community justice is just one of its most important strategies, but it is a precious and immense source to rethink the right from popular values, freeing it from its servile attachment to bourgeois property.

Keywords: Legal decolonization- community justice-Latin American constitutionalism

Resumo: 0 trabalho aborda uma das categorias teóricas mais ricas e dinâmicas sobre a estruturação injusta da realidade latino-americana, aquela revelada pela colonialidade do poder e conhecimento, não 
apenas como uma perspectiva de análise do passado, mas sobretudo como uma reflexão permanente e atual que tem extrema capacidade de penetração em todos os estratos sociais da América Latina. Os estudos descoloniais tornarão visíveis os mecanismos coloniais entranhados nas estruturas institucionais do Estado e da sociedade latino-americana. 0 surgimento de uma sociologia descolonial contribui fortemente para pensar e construir outra possibilidade de justiça, resultado de uma legalidade subalterna que funda novamente a ordem constitucional sobre bases profundamente inovadoras. Seus autores concluem que o processo de descolonização é contínuo, a justiça comunitária é apenas uma de suas estratégias mais importantes, mas é uma fonte preciosa e imensa para repensar o direito a partir dos valores populares, libertando-o de seu laço servil à propriedade burguesa.

Palavras-chave: descolonização legal - justiça comunitária - constitucionalismo latino-americano

Résumé: Le travail traite de l'une des catégories théoriques les plus riches et les plus dynamiques sur la structuration injuste de la réalité latinoaméricaine. C'est ce qui ressort de La colonialité du pouvoir et du savoir, non seulement en tant que perspective de l'analyse Du passé, mais aussi en tant que réflexion permanente et actuelle, doté d'une capacite extrême de pénétration dans toutes les couches sociales de l'Amérique Latine. Les études décoloniales rendront visibles les mécanismes coloniaux enracinés dans les structures institutionnelles de l'État et de la société latinoaméricaine. L'émergence d'une sociologie décoloniale contribue fortement à penser et à construire une autre possibilité de justice, résultat d'une légalité subalterne qui refuse l'ordre constitutionnel sur des bases profondément novatrices. Ce travail conclut que le processus de décolonisation est continu, la justice communautaire n'étant qu'une de ses stratégies les plus importantes mais restant une source précieuse et immense pour repenser le droit des valeurs populaires, le libérant ainsi de son lien avec la propriété bourgeoise.

Mot-clés: décolonisation juridique - justice communautaire - constitutionnalisme latinoaméricain

摘要: 这项工作涉及拉丁美洲现实的不公平结构中最丰富, 最具活力 的理论范畴之一, 是权力和知识的殖民性所揭示的, 不仅是对过去的 分析的视角，而且最重要的是作为永久的反映和目前在拉丁美洲所 
有社会窝中具有极强的渗透能力. 这些殖民地研究将揭示植根于国 家和拉丁美洲社会制度结构的殖民机制. 非殖民地社会学的出现有 力地促进了思考和建立另一种正义的可能性，这是一种在严重创新 基础上拒绝宪法秩序的次级合法性的结果. 其作者得出的结论是,非 殖民化进程是持续的, 社区正义只是其最重要的战略之一, 但它是重 新思考民众价值观权利的宝贵而巨大的来源，使其摆脱对资产阶级 财产的奴役.

关键字: 法律非殖民化, 社区正义, 拉美宪政

\section{Introducción}

Una de las categorías teóricas más ricas y dinámicas sobre la estructuración injusta de la realidad latinoamericana es aquella revelada por la colonialidad del poder y del saber, no solo como una perspectiva de análisis del pasado, sino sobre todo como una reflexión permanente y actual que posee una extrema capacidad de penetración em todas las camadas sociales de América Latina.

La colonialidad permite comprender las características planetarias del poder que se fundó sobre Nuestra América por la constitución y afirmación de un capitalismo mundial que promueve su ideología y su padrón de dominación y explotación, desde el primer momento de la invasión territorial.

Las décadas finales del siglo XX y las iniciales del siglo XXI son testigos de un proceso que, aunque no está restringido a nuestra región, logró un aporte nuclear a partir de la propuesta de la descolonización política y epistémica que se refleja en diversos campos del conocimiento.

En este sentido, aunque la justicia comunitaria sea una práctica existente en América Latina antes de la colonización, su comprensión y defensa como alternativas emancipatorias del sistema de dominio monista perpetrado por los llamados Estados democráticos y de derecho, encuentra una contribución valiosa de esta epistemología descolonizadora, especialmente cuando se trata de las posibilidades de aportar prácticas contrahegemónicas del derecho y de otros sistemas de justicia no oficiales. 
Siendo así, el objetivo del artículo es comprender la descolonización del derecho que viene de los movimientos del nuevo constitucionalismo latinoamericano a partir del reconocimiento de la justicia comunitaria. En este camino, consideramos fundamental rescatar, en un primer momento, las características básicas de la colonialidad del saber como instrumento teórico adecuado para, en un segundo momento, comprender las características del derecho descolonizado y, finalmente, verificar cómo la justicia comunitaria puede traducirse en una efectiva descolonización del derecho, a partir de la experiencia boliviana.

\section{La descolonización del conocimiento en América Latina}

La reflexión crítica sobre los quinientos años de la invasión europea de América y la contestación al neolibelismo, que marcaron las últimas décadas en América Latina, contaron con un fuerte protagonismo del movimiento indígena en la construcción de un proceso efectivo que resultó en la politización de lo étnico. Confluyeron en ese movimiento el cuestionamiento de los saberes dominantes (colonialidad del saber), como también la insurgencia contra el modelo de estructuración económica y política de un capitalismo salvaje que fue sangrientamente instalada, en gran medida por dictaduras militares (colonialidad del poder), pro-estadounidenses que tuvieron como eje central de sustentación la Doctrina de Seguridad Nacional.

La formación del grupo Modernidad/Colonialidad constituyó una referencia central para los aportes epistémicos de la descolonización ${ }^{3}$. Uno de los principales pensadores de ese grupo fue

\footnotetext{
3 El grupo surgió en el final de la década del noventa, teniendo como marco el encuentro en la Universidad Central de Venezuela en 1998, que reunió a Aníbal Quijano, Fernando Coronil, Edgardo Lander, Arturo Escobar, Walter Mignolo y Enrique Dussel. Planteó un desacuerdo con los presupuestos teóricos de los estudios sobre la poscolonialidad, que tuvo como uno de sus principales autores al lingüista hindú Homi Bhabha, académico de Harvard que desarrolló el concepto de "hibridización" y al crítico literario palestino Edward Said, que fue profesor en Columbia y resultó conocido por su obra Orientalismo de 1978. Posteriormente, surge el grupo de estudios subalternos que se inicia con investigaciones sobre la India y el colonialismo,
} 
el peruano Aníbal Quijano, que tuvo una larga y eminente trayectoria en el pensamiento latinoamericano, protagonista en el desarrollo de la Teoría de la Dependencia y de la Teoría del Colonialismo Interno, siendo la categoría de Colonialidad del Poder una potentísima fuente de inspiración para el análisis de la realidad de América Latina.

En su histórico y fecundo artículo "Colonialidad del Poder, Eurocentrismo y América Latina” presenta la Colonialidad del Poder como un padrón mundial surgido en la invasión europea de América por el cual "Las nuevas identidades históricas producidas sobre la base de la idea de raza, fueron asociadas a la naturaleza de los roles y lugares en la nueva estructura global de control del trabajo. Así, ambos elementos, raza y división del trabajo, quedaron estructuralmente asociados y reforzándose mutuamente, a pesar de que ninguno de los dos era necesariamente dependiente el uno del otro para existir o para cambiar" (Quijano, 2000, p. 204).

En el centro de la "Colonialidad del Poder" está identificado el padrón de poder colonial que constituye la complejidad de los procesos de acumulación capitalista articulados en una jerarquía racial, étnica global y sus clasificaciones derivadas de superior/inferior, desarrollo / subdesarrollo y de los pueblos civilizados / bárbaros. De la misma manera, la idea de "Colonialidad" vincula el proceso de colonización de las Américas y la constitución del sistema-mundo capitalista como parte de un mismo proceso histórico en el siglo XVI. La construcción de la jerarquía racial y étnica global fue simultánea y contemporánea, espacio-temporalmente, con la División Internacional del Trabajo organizada en relaciones Centro-Periferia en escala mundial (Castro-Gómez y Grosfoguel, 2007, p. 18-19).

teniendo como referencia a Antonio Gramsci, Jacques Derrida, Michel Foucault y Ranajit Guha. Otros autores referenciales son Partha Chatterjee, Gayatri Spivak y varios latinoamericanistas que se sumaron como Fernando Coronil y Florencia Mallon, formando el grupo de estudios subalternos. Algunas críticas revelan que a pesar del intento de producir un conocimiento radical y alternativo, reprodujeron el esquema epistémico de los Estudios de área de los Estados Unidos. 
Quijano invita a una profunda y necesaria crítica de la racionalidad moderna. La deconstrucción del paradigma europeo de racionalidad no es solamente indispensable, sino también urgente. Para ello, es dudoso que el camino consista en una negación simple de todas sus categorías, en la disolución de la realidad en el discurso, en la pura negación de la idea y de la perspectiva de totalidad del conocimiento. Más allá de eso, es necesario desprenderse de los vínculos de la racionalidadmodernidad con la colonialidad, rompiendo, en definitiva, con todo poder no constituido en la decisión de las personas libres. Es la instrumentalización de la razón del poder colonial, en primer lugar, lo que produjo paradigmas distorsionados del conocimiento y malogró las promesas liberadoras de la modernidad. La alternativa, entonces, es clara: la destrucción de la colonialidad del poder mundial ${ }^{4}$ (Quijano, 1992, p. 19).

Edgardo Lander realiza su aporte a la colonialidad del poder, destacando que su presupuesto básico es el carácter universal de la experiencia europea, en el que se realiza una "lectura de la totalidad del tiempo y del espacio de la experiencia humana a partir de esta particularidad, (que) se erige una universalidad radicalmente excluyente" (Lander, 2000, p. 16-17).

\footnotetext{
4 Otra figura clave para la episteme descolonizadora es Enrique Dussel, uno de los inspiradores de la Teología y de la Filosofía de la Liberación. Citamos otros autores del movimiento descolonial que se fueron sumando al grupo inicial, sin pretensión de exhaustividad: Arturo Escobar que trabaja una profunda crítica al paradigama del desarrollo; Catherine Walsh, lingüista norteamericana que fue discípula de Paulo Freire; Ramón Grosfoguel, sociólogo portorriqueño que trabaja en Berkeley, California; Santiago Castro-Gómez que desarrolló el concepto de "hybris del punto cero" criticando la ciencia moderno-occidental; el filósofo portorriqueño Nelson Maldonado Torres que desarrolló el concepto de "decolonialidad" y Boaventura de Sousa Santos, con la sociología de las emergencias. Existe también un inmenso aporte del movimiento indígena, de sus propios intelectuales y de los que fueron surgiendo acompañando el movimiento, citamos algunos: Luis Macas, Luis Fernando Sarango Macas, Blanca Chancoso, Mario Bustos, Humberto Cholango, Simón Yampara, Javier Lajo, Alberto Acosta, Pablo Dábalos, Xavier Albó, Raquel Yrigoyen Fajardo y el Grupo Comuna de Bolivia, donde participaron Álvaro García Linera, Luis Tapia, Raúl Prada Alcoreza y Óscar Vega. En México, una serie de intelectuales que acompañaron los movimientos indígenas, especialmente en las luchas por la autonomía: Pablo González Casanova; Rodolfo Stavenhagen, Luis Villoro, Gilberto López y Rivas. En Uruguay, Eduardo Gudynas y Raúl Zibechi.
} 
Según Lander, esa visión universal de la historia está asociada a la idea de progreso y desde entonces se clasifica y se jerarquiza los pueblos, naturalizando la superioridad de los saberes de aquellos que dominan de forma de superar los saberes populares, que son considerados un obstáculo al progreso. Por esta razón es necesario "un esfuerzo de deconstrucción del carácter universal y natural de la sociedad capitalista-liberal (que) requiere el cuestionamiento de las pretensiones de objetividad y neutralidad de los principales instrumentos de naturalización y legitimación de este orden social: el conjunto de saberes que conocemos globalmente como ciencias sociales" (Lander, 2000, p. 12).

Igualmente, Walter Mignolo entiende el llamado "giro decolonial" como una apertura a "formas de vida-otras" y como un "desprendimiento de la retórica de la modernidad y de su imaginario imperial articulado en la retórica de la democracia”, buscando la superación de la matriz colonial del poder (Mignolo, 2007, p. 29-30).

Sumando todos los esfuerzos, consideramos que la descolonización epistemológica abre caminos para: a) la construcción de un pensamiento latinoamericano original; b) la comunicación intercultural en un ambiente de equidad que posibilite el diálogo de saberes; c) la relación entre lo cultural y lo político-económico, superando algunas dicotomías empobrecedoras y siguiendo la línea de politización de lo étnico que fue profundizada por el movimiento indígena; d) el combate y la presentación de alternativas frente al "servilismo intelectual" presente en el ámbito académico caracterizado por "la adopción, casi ciega de los modelos teóricos y conceptos desadaptados a nuestro medio, pero que tienen sus referentes en Europa y los Estados Unidos" (Fals Borda, 2009, p. 224); e) la posibilidad de respaldar con la "insurgencia epistémica" los caminos de la "insurgencia política", fortaleciendo caminos revolucionarios de inspiración autóctona al "poner en escena lógicas, racionalidades y pensamientos distintos" (Walsh, 2008, p. 134); f) la posibilidad de un diálogo con otras vertientes revolucionarias que aportaron su lucha y su pensamiento en América Latina (marxismo, cristianismo 
de liberación, nacionalismos anti-imperialistas, populismos de izquierda, anarquismo, etc.), ayudando a que den lo mejor de sí al abandonar sus elementos occidentalizados y posibilitando una relectura de sus propios y valiosos contenidos desde los aspectos más profundos de nuestra región; g) el diálogo entre los pueblos del Sur Político (Santos, 2002, p. 380) abarcando "el espacio planetario de la expansión colonial / imperial" (Mignolo, 2007, p. 45).

Para los objetivos del presente artículo, se resalta el compromiso con los saberes de los pueblos latinoamericanos, que deben producir un conocimiento no solo "para" o "sobre" América Latina, sino sobre todo "desde" nuestra región. La elección del lugar "desde donde" construimos el conocimiento nos provee tanto de las cercanías como de las distancias (epistémicas, afectivas y políticas) frente a los problemas que abordamos y, principalmente, a sus sujetos históricos. La elección y el compromiso con el lugar tiene una importancia vital en el camino del conocimiento que surja de las sabidurías de las luchas populares latinoamericanas.

Generalmente, el conocimiento pro-oligárquico, lamentablemente dominante en nuestra academia, busca ocultar el lugar, alegando neutralidad y objetividad científica. Pocos admiten que el discurso cientificista esconde su compromiso con las estructuras de poder. De todas formas, existen también existen sectores de la academia que manifiestan apoyo ético y político con las mayorías populares, pero que no pudieron o no quisieron trascender ese compromiso a lo epistémico al reproducir un conocimiento marcado por el eurocentrismo y, por tanto, por la colonialidad.

La comprensión de la justicia comunitaria exige la manifestación de ese compromiso ético, que se traduce en una postura teórica que promueva el giro decolonial, ya que resulta de práctica y saberes que subsistieron marginalizados de las epistemologías científicas de América Latina, especialmente cuando se trata de filosofía del derecho cuya matriz occidental y profundamente arraigada en la cultura jurídica latinoamericana, como será expresado en la próxima sección. 


\section{Descolonización del Derecho y el Nuevo Constitucionalismo}

El paradigma jurídico dominante es caracterizado por el monismo, la estatalidad, la racionalidad formal y por la defensa dogmática de la seguridad jurídica. La legitimación del derecho en los Estados modernos ocurre por el monopolio de la fuerza, por la despersonalización del poder, por el sentido de legalidad escrita y legitimidad jurídico-racional (Wolkmer, 2006). Tal fórmula, forjada en el seno de las revoluciones liberales, escamotea la estructura capitalista que sostiene los intereses de la clase dominante en las relaciones de poder verticalizadas y estatalizadas.

La fuente única de producción del derecho es el Estado y el criterio de validez formal de las reglas substituye los criterios de eficacia y de aceptación social que actúan en otras fuentes de justicia. La filosofía del positivismo normativo, que tanto influenció la herencia del derecho en América Latina, alejó por completo las experiencias normativas auténticas de la región, sobre todo aquellas que están presentes en el mundo indígena, que fueron absolutamente excluidas del ordenamiento oficial. El derecho estatal, cuando regulaba intereses indígenas, lo hacía de forma ultrajante, sea atribuyendoles la incapacidad civil o secuestrando el status jurídico de ciudadanía, principio básico para usufructuar las garantías normativas del Estado liberal.

Aún estando en crisis, el monismo sigue siendo el pilar estructurante del Estado de derecho contemporáneo, al lado del dogma de la seguridad jurídica. Siendo así, monismo y seguridad jurídica constituyen dos mitos que sostienen las estrategias de la colonización del derecho, cuya función primordial es la garantía de las libertades negativas e individuales contra el Estado para asegurar el libre mercado y reprimir penalmente a todos aquellos que no alcanzan el status de ciudadanía.

El mito del monismo jurídico, de acuerdo con Amaya, presenta una doble tendencia, tanto de inclusión como de exclusión:

De inclusión porque implica selección y articulación de normas y estructuras producidas en la sociedad, atrayendo 
partes de los sistemas jurídicos socialmente producidos que se van incorporando al derecho estatal centralizador mediante la asignación de competencias y posiciones dentro de la jerarquía normativa. De exclusión, porque la selección implica el rechazo de construcciones normativas que se derivan externas al orden jurídico para perseguirlo, deslegitimarlo o dispersarlo. (Amaya, 2002, p. 51).

La colonización se en los dos aspectos: en la inclusión ya que la incorporación de normas de otros sistemas jurídicos desautoriza otros intérpretes de la ley que no sean los funcionarios al servicio del poder; y en la exclusión, especialmente por la imposición hegemónica del sistema jurídico oficial sobre los demás sistemas jurídicos.

$\mathrm{Y}$, en el caso, de la seguridad jurídica se conforma como artificio discursivo que busca legitimar la centralidad de la producción y la aplicación del derecho en nombre de una justicia supuestamente garante de la estabilidad social, aunque excluyente y profundamente represora en relación a los marginalizados del sistema social.

Frente a la realidad de un derecho claramente colonizado, ordenado y sostenido por el capitalismo, tanto en su conformación teórica como en su práctica, existen algunas prácticas que ayudan a visibilizar los caminos de la descolonización en un ámbito tan impermeable a las perspectivas originarias y autónomas.

Uno de los elementos claves de este proceso es el movimiento que viene siendo denominado como "Nuevo Constitucionalismo Latinoamericano" cuyas expresiones más eminentes son las Constituciones Ecuatoriana de 2008 y la Boliviana de 2009, que fueron marcadas fundamentalmente por las contribuciones de los movimientos indígenas de esos países.

Se trata de un constitucionalismo real (Viciano P.; Martínez D., 2010), pluricultural (Yrigoyen F., 2011) o transformador (Santos, 2010). Según Yrigoyen Fajardo (2011, p. 142):

Las Constituciones de este ciclo incorporan un nuevo y largo listado de derechos indígenas, en el marco de la adopción del Convenio 169 de la Organización 
Internacional del Trabajo sobre Pueblos Indígenas y Tribales en Países Independientes (1989). Esos derechos incluyen la oficialización de los idiomas indígenas, la educación bilingüe intercultural, el derecho sobre las tierras, la consulta y nuevas formas de participación, entre otros. (...) Las Constituciones de este ciclo reconocen a las autoridades indígenas, con sus propias normas y procedimientos o su derecho consuetudinario y funciones jurisdiccionales o de justicia.

Para Santos el constitucionalismo transformador actúa "a través de una institucionalidad nueva (plurinacionalidad), una territorialidad nueva (autonomías asimétricas), una legalidad nueva (pluralismo jurídico), un régimen político nuevo (democracia intercultural) y nuevas subjetividades individuales $\mathrm{y}$ colectivas (individuos, comunidades, naciones, pueblos, nacionalidades)" (p. 72).

De los distintos elementos que podríamos destacar, indicaremos tres que son fundamentales para el presente artículo, que son: la plurinacionalidad, el pluralismo jurídico y la presencia de principios indígenas en la parte dogmática de las Constituciones.

El Estado Plurinacional es la modificación más importante en la estructura y la ideología del Estado-Nación que ocurrió desde su época fundacional. Implica, entre otras cosas, el intento de efectivizar en el ámbito político institucional una realidad negada por la Colonialidad del Poder: que existen naciones que preexisten al Estado liberal y que, por tanto, tienen un derecho propio que debe ser respetado. La plurinacionalidad requiere que se organice un sistema de diálogo entre saberes, criterios y prácticas de diferentes derechos que están actuando en los territorios, inclusive considerando algunas características internacionales de esos derechos.

Otro elemento, íntimamente vinculado al anterior es el pluralismo jurídico comprendido especialmente a partir del ejercicio y de la lucha de los movimientos indígenas. Este pluralismo jurídico es "producto de lo que podríamos llamar la capacidad ancestral y 'popular' de convivencia y de resolución de conflictos” 
(Friggeri, 2014, p. 177-178). El Estado deja de ser la única fuente de derecho y reconoce que existe un "derecho que nace del pueblo" (De la Torre R., 1986) y que debe ser "elevado" en virtud de su soberanía y autodeterminación.

El tercer elemento es fundamental, sobre todo porque en las referidas Constituciones están asegurados los principios indígenas en convivencia con los principios consagrados occidentalmente en la historia de los derechos humanos liberales. La presencia de valores indígenas en la parte dogmática de los Constituciones da un carácter referencial y de potencialidad para dar forma a la interpretación de las leyes y, por consecuencia, hacer respetar la jurisdicción indígena originaria.

Según Uprimny (2011, p. 113) junto al reconocimiento amplio de los derechos indígenas, la parte dogmática de las referidas Constituciones incorporaron derechos civiles y políticos heredados de tradiciones demoliberales, estableciendo ampliamente derechos sociales, económicos y culturales, pero presentan su gran diferencia en el reconocimiento de las distintas formas de derechos colectivos como, por ejemplo, el derecho al medio ambiente y el derecho de la naturaleza (Pachamama) en la Constitución Ecuatoriana, que pasa a ser sujeto jurídico por lo menos formalmente, así como la incorporación de la cosmovisión indígena en ambas constituciones.

Es, por lo tanto, a partir de la Plurinacionalidad, el Pluralismo Jurídico y del reconocimiento de valores comunitarios que se comienza a comprender la función y el espacio de la justicia comunitaria en el cuerpo constitucional, como será expuesto en la próxima sección.

\section{Justicia comunitaria en el Nuevo Constitucionalismo Latinoamericano}

La descolonización del derecho en el proceso constitucional boliviano derivó en el reconocimiento del pluralismo jurídico en su artículo 179: 
Artículo 179.

I. La función judicial es única. La jurisdicción ordinaria se ejerce por el Tribunal Supremo de Justicia, los tribunales departamentales de justicia, los tribunales de sentencia y los jueces; la jurisdicción agroambiental por el Tribunal y jueces agroambientales; la jurisdicción indígena originaria campesina se ejerce por sus propias autoridades; existirán jurisdicciones especializadas reguladas por la ley.

II. La jurisdicción ordinaria y la jurisdicción indígena originaria campesina gozarán de igual jerarquía.

III. La justicia constitucional se ejerce por el Tribunal Constitucional Plurinacional.

IV. El Consejo de la Magistratura es parte del Órgano Judicial.

En un mismo dispositivo, la Constitución boliviana supera el proceso de inclusión y exclusión monista en dos decisivas incorporaciones: primero por el reconocimiento de la justicia comunitaria al establecer igual jerarquía entre la jurisdicción ordinaria y la jurisdicción indígena; segundo por la creación de un Tribunal Constitucional Plurinacional - TCP constituido por magistrados electos por sufragio universal, respetando la proporcionalidad indígena lo cual es resultado de la observancia del criterio de plurinacionalidad.

La forma de coordinación entre los dos sistemas de justicia fue reglamentada por la Ley de Deslinde Jurisdiccional - Ley 73 de diciembre de 2010 - que fue criticada por algunos investigadores al considerar que el dispositivo legal blinda la justicia ordinaria contra los excesos de la justicia comunitaria, no obstante reafirmar la necesidad de cumplimiento de las decisiones originarias (Wolkmer; Ferrazzo, 2016, p. 68).\}

El Tribunal Constitucional Plurinacional debe velar por los principios de plurinacionalidad, interculturalidad, pluralismo jurídico y complementariedad, según la Ley 27 del 6 de julio de 2010 que organiza su funcionamiento. Una de las estructuras del Tribunal (sala especializada) debe tratar acerca de las consultas formuladas por las autoridades indígenas, en carácter exclusivo. 
Para Wolkmer y Ferrazzo "Em geral, as decisões conduzem a uma mitigação do pluralismo jurídico, reafirmando a supremacia do direito estatal, tornando ineficaz a jurisdição indígena, ou ainda, eventualmente, implicando na criminalização tácita da jurisdição indígena" (2016, p. 68-70). Por otro lado, reconocen los autores que también existen casos positivos, como en la sentencia 1422 de 2012 que reconoció la hermenéutica plural o multidimensional que interpreta vivencias y experiencias a partir de la materialidad concreta del pueblo indígena originario.

En el análisis de la jurisprudencia del TCP hay una clara limitación de la jurisdicción comunitaria indígena en cuanto a la violación de los derechos fundamentales, reforzando lo que fue constatado por los autores Wolkmer; Ferrazo (2016, p. 68-70). En el mismo sentido, la sentencia 952 de 2017 - S2 que trata sobre la decisión de expulsión, por la justicia originaria, de indígenas de la comunidad Chiara Araña, en el Departamento de La Paz en razón de un delito penal, reconoce que:

...si bien la jurisdicción indígena originaria goza de reconocimiento en la Ley Fundamental, por el reconocimiento plural del Estado Boliviano; el principio de unidad de la función judicial, implica que todas las jurisdicciones deban cumplir y respetar los derechos fundamentales y garantías constitucionales de las personas, en el marco de la obediencia máxima a la Constitución Política del Estado, límites que le son impuestos pese a su reconocimiento, tomando en cuenta la máxima eficacia de los derechos fundamentales y garantías constitucionales de las personas, así como la materialización de los principios, valores y fines que fundamentan la Norma Suprema en defensa del carácter supremo que le atinge.

En cambio, la Declaración Constitucional 88 de 2017 que delibera sobre una consulta de autoridades indígenas originarias campesinas sobre la aplicación de normas jurídicas a un caso concreto reconoció la autonomía de la justicia indígena para solucionar un conflicto de tierras en la Estancia Tansilla, que se localiza en el Departamento de Potosí. 
En la decisión, además de reconocer los principios indígena suma qamaña ("vivir bien"), qhapaq ñan (camino o vida noble) que orientaron a la comunidad indígena a adoptar una decisión comunitaria, el Tribunal fundamentó la declaración de aplicabilidad al caso concreto de la determinación adoptada por las autoridades originarias del Ayllu Achuma "Khucho" tanto en la Convención 169 de la OIT, como en las normas constitucionales que establecen la autodeterminación de los pueblos indígenas y hasta en la misma jurisprudencia de la Corte Interamericana de Derechos Humanos en el caso "Comunidad Mayagna (Sumo) Awas Tingni versus Nicaragua", que reconoció la forma comunal de los indígenas de propiedad colectiva de la tierra. Para el TCP:

La Constitución Política del Estado Plurinacional con relación a la gestión territorial autónoma es clara y ratifica todo lo señalado en el párrafo anterior, dejando simplemente aclarado que debe tomarse el derecho de los terceros que hayan sido "legítimamente adquiridos", resaltamos esta última expresión por las consecuencias históricas por los que tramitó la territorialidad indígena, no todos los terceros poseen de manera legítima la tierra, muchas han sido producto de imposiciones de negociados y de despojos bajo el manto de la legalidad, siendo imperativo la reconstitución territorial en el marco de la Plurinacionalidad, al respecto la Ley fundamental en el art. 30.II.17 expresa que los pueblos indígenas tienen derechos: "A la gestión territorial indígena autónoma, y al uso y aprovechamiento exclusivo de los recursos naturales renovables existentes en su territorio sin perjuicio de los derechos legítimamente adquiridos por terceros".

De esa forma, podemos concluir de forma parcial que la jurisprudencia del TPC tiende a reconocer los derechos colectivos indígenas, pero subyuga la justicia comunitaria a los derechos fundamentales cuando esta viola los derechos individuales de matriz liberal occidental.

Por lo tanto, debemos entender el pluralismo constitucional boliviano en una triple perspectiva: primero, por el reconocimiento de otros sistemas normativos por el sistema 
hegemónico oficial que permite la aceptación de los procesos decisorios de la justicia comunitaria, siempre y desde que limitados por los principios de unidad jurisdiccional, lo que puede traducirse en la superposición de los principios del monismo frente a los principios indígenas; segundo, por la inclusión de principios indígenas como fuentes oficiales en el sistema hegemónico oficial; tercero, por la inclusión de representantes indígenas electos para ejercer las funciones en la corte constitucional, garantizando así la correcta interpretación de los valores de la cosmovisión indígena.

La conformación de esa correlación entre la justicia comunitaria y la jurisdicción estatal resulta del conflicto entre la legalidad demo-liberal y la legalidad subalterna que se expresa en cuatro clases de sociabilidad: violencia, coexistencia, reconciliación y convivencia. La violencia que resulta de la supresión y subordinación de la legalidad subalterna por el sistema oficial. La coexistencia es la no hibridización de los sistemas, típicos del apartheid cultural que produce la incomunicabilidad entre ellos. La reconciliación que se fundamenta en la justicia restaurativa para reparar las violaciones del pasado y la convivencia que es una reconciliación que mira al futuro, cuando las violaciones del pasado fueran superadas, facilitando los intercambios tendencialmente iguales y la autoridad compartida entre los dos sistemas. En último caso, el sistema oficial y el subalterno son considerados visiones alternativas que, cuando entran en conflicto, son solucionados según reglas consensuadas (Santos, 2010, p. 89-90).

El pluralismo boliviano presenta una sociabilidad que aprecia la convivencia de los dos sistemas, especialmente en razón del reconocimiento de la plurinacionalidad. En la práctica judicial observamos una tendencia a reconocer la autonomía del sistema indígena en relación a los derechos colectivos, aplicando la previsión constitucional de garantía de los derechos fundamentales en caso de conflicto relativos especialmente a los derechos individuales, como se ha visto. Por tanto, es posible inferir que las reglas consensuadas están siendo consideradas, aunque exista una notable jerarquía entre los dos sistemas. 
Siendo así, independientemente de las limitaciones y críticas que puedan surgir de los conflictos provenientes de la zona de contacto entre los sistemas, es innegable el profundo proceso transformador realizado por la Constitucion Boliviana, especialmente por la preponderancia del plurinacionalismo, fruto de los movimientos indígenas que se hicieron presentes en la Asamblea Constituyente.

No hay, entonces, como comprender la descolonización del derecho por el reconocimiento de la justicia comunitaria y el nuevo constitucionalismo sin que se lleve en consideración el protagonismo y activismo del movimiento indígena.

\section{Consideraciones finales}

La descolonización del derecho requiere un diálogo de saberes cuya implementación se enfrenta con una dura resistencia de los sectores más oligárquicos de la magistratura porque altera la configuración del poder económico que siempre fue el fundamento del Estado liberal en América Latina.

La prevalencia del pluralismo jurídico es, incluso, fuertemente contradictoria con las normas constitucionales que protegen la propiedad privada. De allí la importancia de comprender las potencialidades del nuevo constitucionalismo latinoamericano para consolidar prácticas jurídicas emancipatorias que están orientadas y al servicio de las mayorías populares.

Los estudios descoloniales permitirán visibilizar los mecanismos coloniales arraigados en las estructuras institucionales del Estado y de la sociedad latinoamericana. La emergencia de una sociología decolonial contribuye vivamente para pensar y construir otra posibilidad de justicia, resultado de una legalidad subalterna que refunda el orden constitucional sobre bases profundamente innovadoras.

Como se ha visto en el artículo, no se trata solamente de dar autonomía para la justicia comunitaria o de reconocer las fuentes de los sistemas normativos no oficiales, sino de incluir otros pilares que sostengan la estructura estatal como la 
plurinacionalidad, el pluralismo y los valores indígenas que fragilizan los fundamentos del Estado democrático liberal, sin, con todo, substituirlos.

El proceso de descolonización es continuo, la justicia comunitaria es apenas una de sus estrategias más importantes, pero es una fuente preciosa e inmensa para repensar el derecho a partir de los valores populares, libertándolo de su atadura servil a la propiedad burguesa.

\section{Bibliografia}

AMAYA, Edgar Ardilla (2002). Pluralismo jurídico: apuntes para el debate. El outro derecho, número 26-27, pp. 49-61.

CASTRO-GÓMEZ, Santiago., GROSFOGUEL, Ramon (Comp). (2007) El giro decolonial: reflexiones para una diversidad epistémica más allá del capitalismo global. Colombia, Bogotá: Siglo del Hombre.

DE LA TORRE RANGEL, Jesús Antonio (1986). El Derecho que nace del pueblo. México, Aguascalientes: CIRA.

FALS BORDA, Orlando (2009). Una sociología sentipensante para América Latina. Colômbia, Bogotá: CLACSO / Siglo del Hombre.

FRIGGERI, Félix Pablo (2014). 'Alteridad Constitucional'. Nuevo Constitucionalismo y principios indígenas: de la incoherencia a la revolución. Cadernos Prolam/USP, 13(25), pp. 173-187.

LANDER, Edgardo (2000). Ciencias sociales: saberes coloniales y eurocéntricos. En Lander, Edgardo (ed.), La colonialidad del saber: eurocentrismo y ciencias sociales. Perspectivas latinoamericanas. Argentina, Buenos Aires: CLACSO, pp. 11-40.

MIGNOLO, Walter (2007). La opción des-colonial, desprendimiento y apertura: un manifiesto y un caso. En CASTRO-GÓMEZ, Santiago., GROSFOGUEL, Ramon (Comp), El giro decolonial: reflexiones para una diversidad epistémica más allá del capitalismo global. Colômbia, Bogotá: Siglo del Hombre; Universidad Central; Instituto de Estudios Sociales Contemporáneos y Pontificia Universidad Javeriana, pp. 25-46.

QUIJANO, Aníbal (2000). Colonialidad del poder, eurocentrismo y América Latina. En Lander, Edgardo (comp. ), La colonialidad 
del saber: eurocentrismo y ciencias sociales. Perspectivas latinoamericanas. Argentina, Buenos Aires: CLACSO, pp. 201-248.

QUIJANO, Aníbal (1992). Colonialidad y Modernidad/Racionalidad. Perú Indígena, 13(29), pp. 11-20.

SANTOS, Boaventura de Sousa (2002). A Crítica da Razão Indolente: contra o desperdicio da experiência. Para um novo senso comum. A ciência, o direito e a politica na transição paradigmática. São Paulo: Cortez.

SANTOS, Boaventura de Souza (2010). Refundación del Estado en América Latina Perspectivas desde una epistemología del Sur. Peru, Lima: Instituto Internacional de Derecho y Sociedade.

UPRIMNY, Rodrigo (2011). Las transformaciones constitucionales recientes en América Latina: tendencias y desafíos. En César Rodríguez Garavito (Coord), El derecho en América Latina: un mapa para el pensamiento jurídico del siglo XXI. Argentina, Buenos Aires: Siglo Veintiuno Editores, pp. 109-137.

VICIANO PASTOR, Roberto; MARTÍNEZ DALMAU, Rubén (2010). Los processos constituyentes latino-americanos y el nuevo paradigma constitucional. IUS 25, Revista del Instituto de Ciencias Jurídicas de Puebla, pp. 7-29.

WALSH, Catherine (2008). "Interculturalidad, Plurinacionalidad y Decolonialidad: las insurgencias político-epistémicas de refundar el Estado". Tabula rasa, $\mathrm{n}^{\circ}$ 9, pp. 131-152.

WOLKMER, Antonio Carlos (2006). Pluralismo jurídico: fundamentos de una nueva cultural del derecho. Espanha, Sevilla, Editorial Mad.

WOLKMER, Antonio Carlos., FERRAZO, Débora (2016). Sistemas Plurais de Direito: desde Práticas Sociais e Insurgências LatinoAmericanas. Direito, Estado e Sociedade, n.48, pp. 47-75.

YRIGOYEN FAJARDO, Raquel Z. (2011). El horizonte del constitucionalismo pluralista: del multiculturalismo a la descolonización. En César Rodríguez Garavito (Coord), El derecho en América Latina: un mapa para el pensamiento jurídico del siglo XXI. Argentina, Buenos Aires: Siglo Veintiuno Editores, pp. 139-159. 